\title{
Ages of Onset of DSM-III Anxiety Disorders
}

\author{
Bruce A. Thyer, Richard T. Parrish, George C. Curtis, Randolph M. Nesse, and \\ Oliver G. Cameron
}

The Diagnostic and Statistical Manual (DSM-III) contains little specific information pertaining to the ages of onset of anxiety disorders. Such information is of clinical and research value in understanding the natural history of mental illnesses, in determining which of several possible etiologies for a given diagnosis may be relevant for a particular patient, and in testing theories of psychopathology or pathophysiology. Age-of-onset data is presented for 423 psychiatric outpatients seen at a University Hospital-based anxiety disorders program. All adult anxiety disorders are represented except posttraumatic stress disorder. The relevance of this information is discussed in terms of past research on ages of onset of the anxiety disorders, and in its bearing on the psychiatric diagnosis of these conditions.

$\mathrm{E}$ MPIRICAL data on the onset of psychiatric disorders is important for a variety of clinical and research purposes. For example, this information is necessary to understand the natural history of mental illnesses. In addition, ageof-onset information can be useful in determining which of several etiologies is responsible for a disorder in a given individual. Finally, such data may support or refute various etiologic theories of psychopathology or pathophysiology. For example, early studies involving small numbers of agoraphobics reported a bimodal age of onset for that disorder. ${ }^{1,2}$ This observation has been cited as support for Klein's theory ${ }^{2,3}$ that agoraphobia may result from either early childhood separation anxiety or endocrine abnormalities.

The Diagnostic and Statistical Manual (DSM-III), while rich in phenomenological data, unfortunately provides rather limited information on the natural history and etiology of various disorders. ${ }^{4}$ The chapter on anxiety disorders illustrates this. Each of the eight separate disorders has, at best, a sentence or two about age of onset, and this information is often quite vague or (see Table I) undocumented.

Better data is needed regarding the ages of onset of the anxiety disorders. Sheehan et al. ${ }^{5}$ is one of the few large group studies to obtain age-of-onset information related to phobias systematically. One hundred patients presenting with "endogenous anxiety" (a combination of the DSM-III categories of panic disorder, agoraphobia with panic attacks, and generalized anxiety disorder) had an unimodal age of onset with a mean of 24.1 years. A second series of patients $(N=62)$ with what Sheehan has labelled "exogenous anxiety" (apparently corresponding to the DSM-III categories of simple phobia and social phobia) had a mean age of onset of 19.7 years, with ages of onset extremely positively skewed. The difference in mean age of onset between endogenous and exogenous anxiety was statistically significant $(P<.01)$, suggesting that these disorders may represent differing populations (or diagnostic categories). Furthermore, the different shapes of the his-

From Bruce A. Thyer, Ph.D., Richard T. Parrish, B.A., Geonge C. Curtis, M.D., Randolph M. Nesse, M.D., and Oliver G. Cameron, M.D., Ph.D., Department of Psychiatry. The University of Michigan Medical School, Ann Arbor, Michigan.

Address reprint requests to George C. Curtis, M.D., Department of Psychiatry, Box 011, APH-5, University of Michigan Hospital, Ann Arbor, MI 48109

(c) 1985 by Grune \& Stratton, Inc.

$0010-440 X / 85 / 2602-0002 \$ 03.00 / 0$ 
Table 1. Age of Onset Information for Anxiety Disorders Provided in DSM-II'

\begin{tabular}{|c|c|}
\hline Diagnosis & Age-of-Onset Information \\
\hline $\begin{array}{l}\text { Agoraphobia with or without panic at- } \\
\text { tacks }\end{array}$ & $\begin{array}{l}\text { "Most frequently the onset is in the late teens or early } \\
20 \mathrm{~s} \text {, but it can be much later." }\end{array}$ \\
\hline Social phobia & $\begin{array}{l}\text { "This disorder often begins in late childhood or early } \\
\text { adolescence." }\end{array}$ \\
\hline Simple phobia & $\begin{array}{l}\text { "Age of onset varies, but animal phobias nearly always } \\
\text { begin in childhood." }\end{array}$ \\
\hline Panic disorder & $\begin{array}{l}\text { "This disorder often begins in late adolescence or early } \\
\text { adult life, but may occur initially in mid-adult life." }\end{array}$ \\
\hline Generalized anxiety disorder & "No information." \\
\hline Obsessive-compulsive disorder & $\begin{array}{l}\text { "Although the disorder usually begins in adolescence } \\
\text { or early adulthood, it may begin in childhood." }\end{array}$ \\
\hline Posttraumatic stress disorder & $\begin{array}{l}\text { "This disorder can occur at any age, including child- } \\
\text { hood." }\end{array}$ \\
\hline
\end{tabular}

'Pp 225-239.

tograms of ages of onset suggest different etiologies for endogenous and exogenous anxiety.

The current study was undertaken to provide more specific information about the ages of onset of adult anxiety disorders as defined by the DSM-III. This information has been previously unavailable. The report by Sheehan et al. ${ }^{5}$ classified several DSM-III categories together under the labels of endogenous or exogenous anxiety. This may possibly obscure important distinctions between these disorders. Alternatively, empirical inquiry may well support Sheehan's simplified classification schema for anxiety disorders..$^{5-7}$

\section{MATERIALS AND METHODS}

\section{Subjects}

Age-of-onset diagnosis and gender information were culled from the files of all patients seen at the Anxiety Disorders program of the Department of Psychiatry at the University of Michigan Hospitals between the years 1978 and early 1984. A clinician experienced in the use of the DSM-III criteria had assigned an Axis I diagnosis to each of these patients.

\section{RESULTS}

Data on the patients' gender distribution, by diagnosis, is presented in Table 2. Each of the adult anxiety disorders, with the exception of posttraumatic stress disorder, is represented. An overall chi-square analysis revealed that women constituted a significantly greater proportion of the patients seeking treatment $\left(\chi^{2}=\right.$ $26.1, P<.001$ ), forming a clear majority of the agoraphobics, simple phobics, panic disorder patients, and obsessive-compulsives. The gender differences occurring in social phobia and generalized anxiety disorder do not appear remarkable. The DSM-III suggests that agoraphobia with and without panic attacks, simple phobia, and panic disorder are diagnosed more commonly in women, and that men and women present with equal frequency for the treatment of obsessive-compulsive disorder. It does not provide any information regarding expected sex ratios for social phobics or generalizd anxiety disorder. Our data support the DSM-III positions regarding gender distribution, except for obsessive-compulsive disorder, and also suggest that approximately equal sex ratios exist for social phobia and gen- 
Table 2. Gender Distribution of Anxiety Disorders

\begin{tabular}{|c|c|c|c|c|}
\hline \multirow[b]{3}{*}{ Diagnosis } & \multicolumn{4}{|c|}{ Gender } \\
\hline & \multicolumn{2}{|c|}{ Female } & \multicolumn{2}{|c|}{ Male } \\
\hline & $N$ & $(\%)$ & $N$ & $(\%)$ \\
\hline Agoraphobia with panic attacks & 76 & $(80)$ & 19 & (20) \\
\hline Agoraphobia without panic attacks & 17 & (85) & 3 & (15) \\
\hline Simple phobia & 110 & $(72)$ & 42 & (28) \\
\hline Social phobia & 22 & (52) & 20 & $(48)$ \\
\hline Obsessive-compulsive disorder & 16 & (59) & 11 & (41) \\
\hline Panic disorder & 35 & (57) & 27 & (43) \\
\hline Generalized anxiety disorder & 11 & (44) & 14 & (56) \\
\hline Total & 287 & (68) & 136 & (32) \\
\hline
\end{tabular}

eralized anxiety disorder. Data based upon clinic patients, it should be noted, may have little bearing on prevalence ratios in the general population.

Information on the ages of onset for each diagnosis is presented in Table 3.

The overall difference occurring among the mean ages of onset for each diagnosis presented in Table 3 was analyzed with a one-way analysis of variance that was significant at the .001 level $[F(6,416)=13.77]$. Scheffe's post hoc paired contrasts for the individual comparisons among diagnostic groups are presented in Table 4.

Simple and social phobias, while not significantly different from each other with respect to mean age of onset, are each significantly different from agoraphobia, with and without panic attacks, and panic disorder. The mean age of onset for simple phobia was significantly earlier than that for obsessive-compulsive disorder, and a similar trend was present for social phobia. Agoraphobia with and without panic attacks, panic disorder, obsessive-compulsive disorder, and gencralized anxiety disorder do not appear to have significantly different ages of onset. The empirical demonstration of two major clusters of anxiety disorders, as defined by age of onset, may support Sheehan's simplified nosological system that postulates two primary forms of anxiety disorder, endogenous anxiety (a metabolic disease?) and exogenous anxiety (phobic disorders acquired by traumatic experiences) . $^{5-7}$

Of equal importance to knowing the mean of onset for the anxiety disorders is documenting the actual distribution of each illness across the years. Accordingly,

Table 3. Age of Onset Information Obtained from 423 Anxiety Disorder Patients

\begin{tabular}{lcccr}
\hline \multicolumn{1}{c}{ Diagnosis } & $\mathrm{N}$ & $\begin{array}{c}\text { Median } \\
\text { Age of Onset } \\
\text { (yrs) }\end{array}$ & $\begin{array}{c}\text { Mean } \\
\text { Age of Onset } \\
\text { (yrs) }\end{array}$ & SD \\
\hline $\begin{array}{l}\text { Agoraphobia with panic } \\
\quad \text { attacks }\end{array}$ & 95 & 25 & 26.3 & 9.1 \\
$\begin{array}{l}\text { Agoraphobia without } \\
\quad \text { panic attacks }\end{array}$ & 20 & 26 & 27.5 & 7.8 \\
$\begin{array}{l}\text { Simple phobia } \\
\begin{array}{l}\text { Social phobia } \\
\text { Obsessive-compulsive }\end{array} \\
\quad \text { disorder }\end{array}$ & 152 & 12 & 16.1 & 13.0 \\
$\begin{array}{l}\text { Panic disorder } \\
\text { Generalized anxiety dis- }\end{array}$ & 27 & 15 & 15.7 & 8.5 \\
$\quad$ order & 62 & 24 & 25.6 & 14.6 \\
& 25 & 27 & 26.6 & 11.5 \\
& & 21 & 22.8 & 12.0
\end{tabular}


Table 4. Probability Levels for Scheffe Post-hoc Paired Contrasts Between Mean Ages of Onset for Anxiety Disorders

\begin{tabular}{|c|c|c|c|c|c|c|c|}
\hline Diagnosis & & & & & & & \\
\hline 1. Simple phobia & - & & & & & & \\
\hline Social phobia & NS & - & & & & & \\
\hline Agoraphobia with panic attacks & .01 & .01 & - & & & & \\
\hline $\begin{array}{l}\text { 4. Agoraphobia without panic at- } \\
\text { tacks }\end{array}$ & .05 & .05 & NS & - & & & \\
\hline Obsessive-compulsive disorder & .05 & NS & NS & NS & - & & \\
\hline Panic disorder & .01 & .01 & NS & NS & NS & - & \\
\hline 7. Generalized anxiety disorder & NS & NS & NS & NS & NS & NS & - \\
\hline & 1 & 2 & 3 & $\begin{array}{c}4 \\
\text { Diagno }\end{array}$ & 5 & 6 & 7 \\
\hline
\end{tabular}

histograms depicting such information are presented in Figure 1 through 7. Patients who stated that they had had their anxiety disorder all their lives were assigned an arbitrary value of three years of age. To facilitate graphic depiction, ages of onset were grouped together in 5-year intervals. Histograms for each of the anxiety disorders are analyzed individually; the findings are compared with the statements found in DSM-III pertaining to age of onset.

\section{Agoraphobia with Panic Attacks}

Hypothesis I: "Most frequently the onset is in the late teens or early twenties but it can be much later." Our data suggest that the DSM-III convention for the age of onset of agoraphobia with panic attacks is correct. Of 95 cases seen, 49 patients $(51 \%)$ reported an onset by age 25 . However, this figure is a bare majority, hence clinicians need to be alert to the possibility that agoraphobia with panic attacks may begin in patients in their $30 \mathrm{~s}$ and $40 \mathrm{~s}$. This histogram (see Figure 1) presents an approximately normal, unimodal distribution of age of onset, with a range from 3 to 51 years.

Our histogram and findings are similar to that reported by Sheehan et al. ${ }^{5}$ and do not replicate the bimodal age of onset previously reported for agoraphobia in smaller sample studies by Klein ${ }^{2}$ and Marks and Gelder.

\section{Agoraphobia Without Panic Attacks}

Hypothesis II: Same as Hypothesis I. This histogram (see Figure 2) includes only 20 patients because this disorder presents rarely at our clinic. This distribution resembles that for agoraphobia with panic attacks and ranges from 16 to 45 years of age. Five of the 20 patients reported an age of onset prior to 25 years. This suggests that the DSM-III convention of an average age of onset in the early $20 \mathrm{~s}$ for agoraphobia without panic attacks may be incorrect.

\section{Simple Phobia}

Hypothesis III: "Age of onset varies, but animal phobias nearly always begin in childhood." This histogram, consisting of 152 patients, presents an extremely positively skewed distribution (see Figure 3).

Seventy-two patients $(47 \%)$ reported an onset in the preteen years with an additional 35 patients (23\%) developing their simple phobia in the teens. Systematic information pertaining to the nature of their phobic stimulus was not extracted from our files, but our clinical experience suggests that the bulk of these patients 


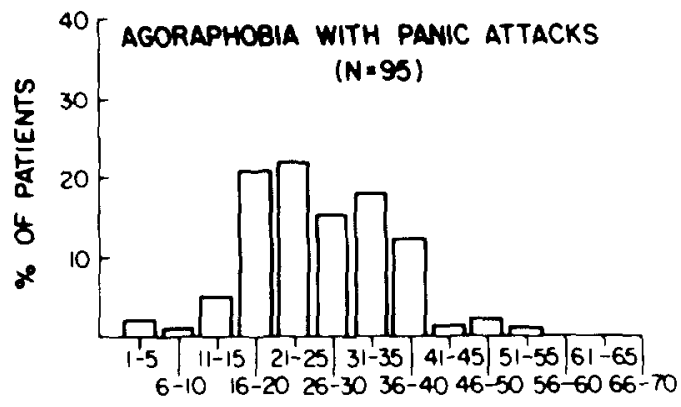

Fig. 1. Distribution of the ages of onset (in 5. year time periods) for 95 patients with agoraphobia with panic attacks.

sought treatment for phobias of small animals such as snakes, spiders, insects, dogs, cats, and rats. Situational fears such as heights, enclosures, flying, and driving constituted the remainder. The onset ranged from 3 to 67 years of age. Our data support the DSM-III position and are in agreement with earlier studies reporting age-of-onset information for monosymptomatic phobias. ${ }^{18.9}$

\section{Social Phobia}

Hypothesis IV: "The disorder often begins in late childhood or early adolescence." This distribution (see Figure 4) comprised 42 patients, ranging in age from 2 to 42 years old and appears slightly positively skewed.

Twenty-eight $(66 \%)$ of the patients reported the onset of their social phobia in their teens or childhood years, but $14(34 \%)$ had an onset in their $20 \mathrm{~s}, 30 \mathrm{~s}$, and in one case, at age 42 . Our data support the DSM-III position regarding the age of onset of social phobia, but in part this is due to the imprecise wording (i.e., "often begins") of the hypothesis. Although the majority of the cases of social phobia appeared to develop in childhood or teenage years, many patients experience initial social phobic symptomatology as an adult.

\section{Obsessive-Compulsive Disorder}

Hypothesis V: "Although the disorder usually begins in adolescence or early adulthood. it may begin in childhood." This histogram of 27 patients ranged in ages from 4 to 60 years (see Figure 5).

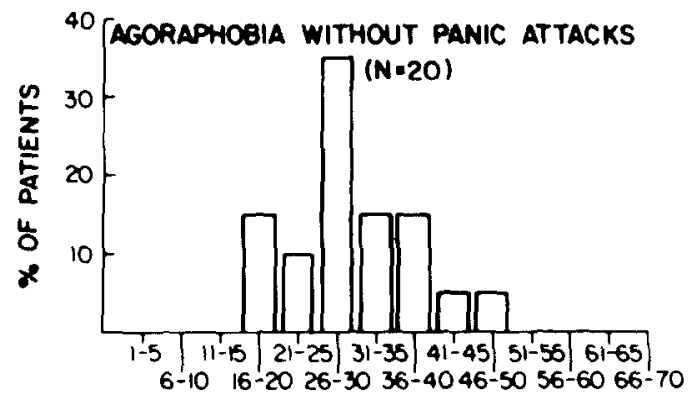

Fig. 2. Distribution of the ages of onset (in 5year time periods) for 20 patients with agoraphobla without panic attacks. 


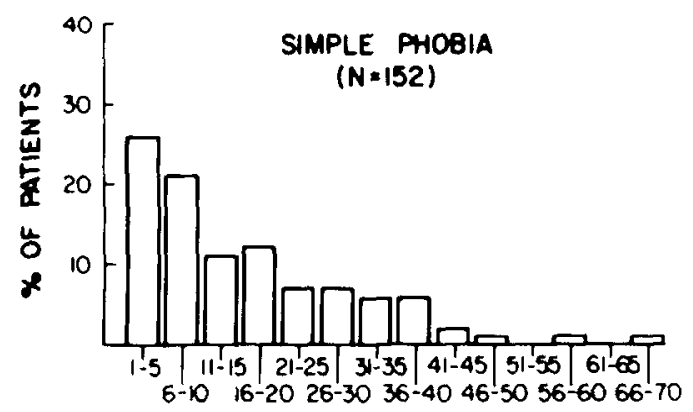

Fig 3. Distribution of the ages of onset (in 5year time periods) for 152 patients with simple phobia.

Thirteen of the patients (48\%) reported an onset between ages 11 and 25 , while $4(15 \%)$ had an onset prior to age 10 . The remaining 10 patients $(37 \%)$ had an onset after age 25. Our data provide partial support for Hypothesis $\mathrm{V}$ but attention should be directed to the significant number of patients who develop obsessivecompulsive disorder after age 25 .

\section{Panic Disorder}

Hypothesis VI: "This disorder often begins in late adolescence or early adult life, but may occur in mid-adult life." This histogram of 62 patients (see Figure 6) ranged from 5 to 51 years of age and has a mean age of onset very similar to that of agoraphobia with panic attacks-26.6 years. This supports the hypothesis of Klein, Sheehan, and the DSM-III-namely, that the phobic restrictions associated with the diagnosis of agoraphobia with panic attacks are the psychological sequelae to the experience of an initial phase of spontaneous attacks of panic. These findings also support the descriptive observation of Freud ${ }^{10}$ who noted that "In the case of agoraphobia etc., we often find the recollection of an anxiety attack; and what the patient actually fears is the occurrence of such an attack under the special conditions in which he believes he cannot escape it."

Twenty-nine patients $(45 \%)$ experienced their initial panic attack after the age of 30 ; hence, as in agoraphobia, clinicians should not rule out the diagnosis of of panic disorder in the older patient. Our data provide limited support for Hypothesis VI, again due to the imprecise wording found in the DSM-III.

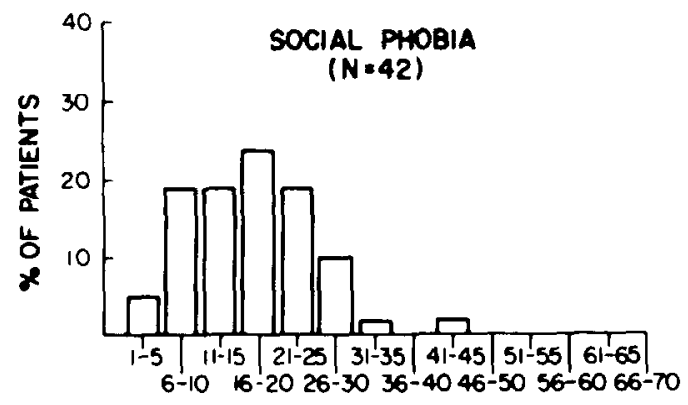

Fig. 4. Distribution of the ages of onset (in 5year time periods) for 42 patients with social phobla. 


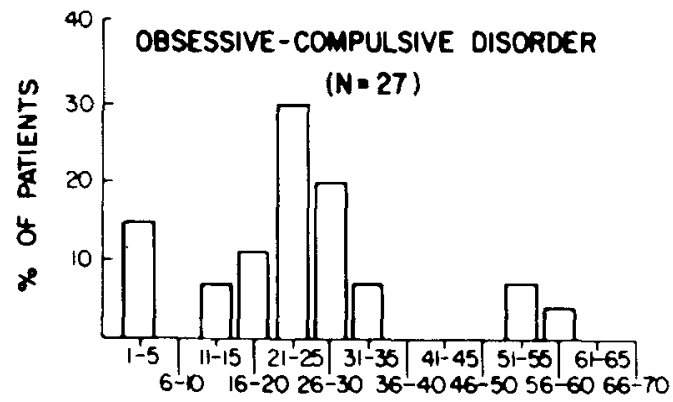

Fig. 5. Distribution of the ages of onset (in 5 . year time periods) for 27 patients with obsessive-compulsive disorder.

\section{Generalized Anxiety Disorder}

Hypothesis VII: "No information." The condition of generalized anxiety disorder represents an entirely new diagnostic category; it and panic disorder are the components of the illness described in DSM-II as "anxiety state." Our histogram (see Figure 7) of 25 such patients appears as a slightly positively skewed curve with a unimodal distribution peaking in the early 20 s. Five patients $(20 \%)$ reported an onset prior to age 18. At the time of such an onset, such patients would technically be given the DSM-III childhood diagnosis of "overanxious disorder." Our limited data provide some initial support for the DSM-III hypothesis that overanxious disorder "may persist into adult life, as an anxiety disorder, such as generalized anxiety disorder or a social phobia."

A tentative proposal for future additions of the DSM-III relating to the age of onset for generalized anxiety disorder is as follows: "This disorder may develop at any age, although the majority of patients have an onset during their third decade.

\section{DISCUSSION}

Our results largely support the DSM-III positions pertaining to age-of-onset information for simple phobia and social phobia, provide more precise data for obsessive-compulsive disorder, panic disorder, and generalized anxiety disorder, and suggest modifications in the age-of-onset information provided for agoraphobia with and without panic attacks.

A chi-square analysis for uniformity of distribution was performed for each of

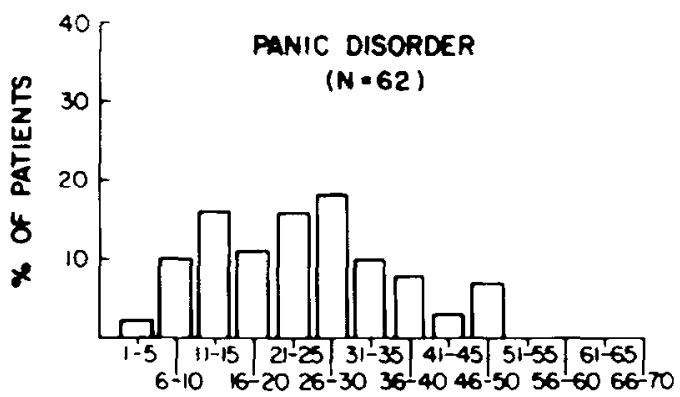

Fig. 6. Distribution of the ages of onset (in 5year time periods) for 62 patients with panic disorder. 


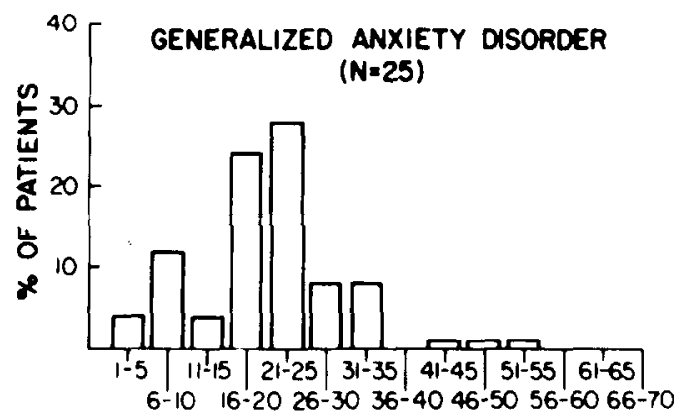

Fig. 7. Distribution of the ages of onset (in 5year time periods) for 25 patients with generalized anxiety disorder.

the age-of-onset histograms found in Figures 1-7. In every case, the ages of onset were not found to be randomly distributed, suggesting that factors other than chance appear to account for each pattern of acquisition.

One possible limitation of our findings is that they were derived from outpatients receiving treatment at a single university hospital-based psychiatric clinic, a sample of anxiety disorders that may not represent the population at large. A further limitation may be that this study relied solely upon the retrospective self-reports of psychiatric patients to obtain a database pertaining to age-of-onset information for DSM-III-defined anxiety disorders. The accuracy of these estimates is open to question but we know of no a priori reasons to assume that patients with any particular anxiety disorder would be more liable to give biased reports. Any distortions, therefore, may be assumed to be equally distributed across the diagnostic categories.

Two recent large group studies of simple phobics have found that the majority of such patients report a history of apparent traumatic conditioning as accounting for the onset of their irrational fears. ${ }^{11,12}$ Corresponding investigations involving agoraphobic patients have failed to find a history of such trauma., ${ }^{913}$ These findings, if replicated, support the hypothesis of different modes of onset for these disorders. Recent studies strongly suggest a biologic basis for the development of the apparently spontaneous panic attacks central to the diagnosis of agoraphobia with panic attacks, and panic disorder. Naturally occurring panic attacks respond well to regimens of tricyclic antidepressants, ${ }^{2,14}$ monoamine-oxidase inhibitors, ${ }^{6}$ or the benzodiazepine alprazolam. ${ }^{15}$ Panic attacks can be provoked in panic disorder or agoraphobic patients by infusions of sodium lactate ${ }^{16-18}$ or yohimbine, ${ }^{19}$ and such induced attacks can be blocked in the laboratory with the same agents found therapeutic in the clinical setting. ${ }^{20,21}$ Family prevalence studies suggest the role of genetic transmission in the susceptibility to developing panic attacks ${ }^{22-27}$; and both panic disorder and agoraphobia with panic attacks are known to be associated with the cardiac anomalies of mitral valve prolapse. ${ }^{28,29}$ The preponderance of the evidence thus suggests that the phobic disorders (simple and social phobia) have a quite different etiology and natural history from the panic-related diagnoses. Our data on the ages of onset for these conditions appear to reflect these differential patterns of acquisition, and may partially support Sheehan's dichotomy of anxiety into two broad categories labelled exogenous anxiety and endogenous anxiety, 
respectively corresponding to the simple and social phobia cluster, and the cluster of agoraphobia with and without panic attacks, panic disorder, and generalized anxiety disorder. ${ }^{5-7}$ However, more evidence is required to confirm the validity of this schema than mere descriptive similarities and differences among ages of onset.

Our data support the hypothesis of a faciliatory period for the development of simple phobias corresponding to the early childhood years. This is in agreement with a number of earlier studies. ${ }^{1.5,8,9}$ Women form the majority of our overall sample $(68 \%)$ and presented in greater numbers in every disorder except generalized anxiety disorder. As noted earlier, this may have little bearing on the prevalence ratios of these disorders in the general population.

This study is the largest to date pertaining to the ages of onset of anxiety disorders as defined by the DSM-III criteria. Attempts by other investigators to replicate these findings are in order, as is further research to increase the sample sizes for the diagnoses of obsessive-compulsive disorder, generalized anxiety disorder, and agoraphobia without panic attacks, in order to ensure a more representative sample of these patients.

\section{REFERENCES}

1. Marks IM, Gelder MG: Different ages on onset in varieties of phobias. Am J Psychiat 123:218-221, 1966

2. Klein DF: Delineation of two drug responsive anxiety syndromes. Psychopharmacologia $5: 397-408,1964$

3. Mendel JGC, Klein DF: Anxiety attacks with subsequent agoraphobia. Compr Psychiat 10:190-195, 1969

4. American Psychiatric Association: Diagnostic and Statistical Manual of Mental Disorders, ed 3. Washington, DC, APA, 1980

5. Sheehan DV, Sheehan KE, Minichiello WE: Age of onset of phobic disorders: A reevaluation. Compr Psychiat 22:544-553, 1981

6. Sheehan DV, Ballenger J, Jacobson G: The treatment of endogenous anxiety with phobic, hysterical, and hypochondriacal symptoms. Arch Gen Psychiat 37:51-59, 1980

7. Sheehan DV: Panic attacks and phobias. N Eng J Med 307:156-158, 1982

8. Jersild AT, Holmes FB: Children's fears. Child Develop Monogr, No. 20, 1935

9. Marks IM: Fears and Phobias. New York, Academic Press, 1969

10. Freud S: Obsessions and compulsions, in Strachey J (ed): The Standard Edition of the Psychological Works of Sigmund Freud, Vol. 3. London. Hogarth Press. 1962, p 81

11. Wolpe J: The dichotomy between classical conditioning and cognitively learned anxiety. J Behav Ther Exp Psychiatry 12:35-42 1981

12. Ost $\mathrm{L}$, Hugdahl $\mathrm{K}$ : Acquisition of phobias and anxiety response patterns in clinical patients. Behav Res Ther 19:439-447, 1981

13. Thorpe G, Burns L: The Agoraphobic Syndrome. Chichester, Wiley, 1983

14. Zitrin C, Klein DF, Woerner M, et al: Treatment of phobias, I. Comparison of imipramine hydrochloride and placebo. Arch Gen Psychiatry 40:125-138, 1983

15. Chouinard G, Annable L, Fontaine R, et al: Alprazolam in the treatment of generalized anxiety and pane disorders: A double blind placebo-controlled study. Psychopharmacology 77:229-233, 1982

16. Liebowitz M, Fyer A, Appleby I, et al: Lactate provocation of panic attacks. Psychopharmacology Bull 19:476-478. 1983

17. Kelly D, Mitchell-Heggs N, Sherman D: Anxiety and the effects of sodium lactate assessed clinically and physiologically. Br J Psychiatry 199:129-144, 1971

18. Pitts FN. McClure JN: Lactate metabolism in anxiety neurosis. New Engl J Med 277:1329-1336, 1967

19. Pitts FN, Allen RE: Beta-adrenergic blockade in the treatment of anxiety, in Roy JM (ed): The Biology of Anxiety. New York, Brunner-Mazel, 1980 
20. Rifkin A: Panic disorder: Response to sodium lactate and treatment with antidepressants. Psychopharmacology Bull 19:432-434, 1983

21. Rifkin A, Klein DF, Dillon D, et al: Blockade by imipramine or desipramine of panic induced by sodium lactate, Am J Psychiatry 138:676-678, 1981

22. Harris E, Noyes R, Crowe RR, et al: Family study of agoraphobics. Arch Gen Psychiatry 40:1061-1064, 1983

23. Crowe RR, Noyes R, Pauls D, et al: A family study of panic disorder. Arch Gen Psychiatry 40:1065-1069, 1983

24. Togerson S: Genetic factors in anxiety disorders. Arch Gen Psychiatry 40:1085-1089, 1983

25. Pauls DL, Bucher KD, Crowe RR, et al: A genetic study of panic disorder pedigrees. Am J Hum Gen 32:639-644, 1980

26. Pauls DL, Noyes R, Crowe RR: The familial prevalence in second degree relatives of patients with anxiety neurosis (panic disorder). J Affect Dis 1:279-285, 1979

27. Crowe RR, Pauls DL, Slyman DJ, et al: A genetic study of anxiety neurosis. Arch Gen Psychiatry 37:77-79, 1980

28. Kantor JS, Zitrin CM, Zeldis SM: Mitral valve prolapse syndrome in agoraphobic patients. Am J Psych 137:467-469, 1980

29. Venkatesh A, Pauls D, Crowe $R$, et al: Mitral valve prolapse in anxiety neurosis (panic attacks). Am Heart J 100:302-305, 1980 